\title{
EVASÃO NO IME/UFG: O PONTO DE VISTA DOS ALUNOS EXCLUÍDOS
}

\author{
Chaiane de Medeiros Rosa \\ Fabiano Fortunato Teixeira dos Sant ${ }^{*}$
}

A evasão da educação superior é um problema que merece muita atenção, pois vem se agravando nos últimos anos. Segundo dados da Sinopse Estatística da Educação Superior de 2015, divulgada pelo Instituto Nacional de Estudos e Pesquisas Educacionais “Anísio Teixeira” (Inep), em 2010, 11,4\% dos alunos abandonaram o curso para o qual foram admitidos, e, em 2014, esse percentual chegou a 49\%. O percentual de evasão na Universidade Federal de Goiás (UFG), assim como no panorama nacional, é muito significativo, tendo atingido 33,9\% em 2014; 35,7\% em 2015; e $27,7 \%$ em 2016.

Diante disso, está sendo desenvolvida uma pesquisa no Instituto de Matemática e Estatística (IME) da Universidade Federal de Goiás (UFG), com o escopo de compreender as causas que levam os alunos a se evadir dos seus cursos de graduação, para pensar em políticas que possam evitar ou reduzir esses problemas.

Essa ação decorre do entendimento de que:

A identificação das possíveis causas da evasão, bem como a gestão de informações sobre esse panorama, é imprescindível para a formulação de políticas de permanência e o planejamento institucional. Trata-se de um insumo básico para a tomada de decisão no que diz respeito às atividades fim da universidade: ensino, pesquisa e extensão (DAVOK; BERNARD, 2016, p. 504).

Nessa direção, este estudo, de caráter quanti-qualitativo, respalda-se em informações de registros acadêmicos na universidade, obtidos por meio de consulta ao Sistema Integrado de Gestão de Atividades Acadêmicas (Sigaa) da instituição. Mas a pesquisa se fundamenta, principalmente, em dados obtidos por meio de questionário. De acordo com Gil (1999, p. 128), esse instrumento “[...] de investigação composta por um número mais ou menos elevado de questões apresentadas por escrito às pessoas, tendo por objetivo o conhecimento de opiniões, crenças, sentimentos, interesses, expectativas, situações vivenciadas, etc."

\footnotetext{
${ }^{(*)}$ Chaiane de Medeiros Rosa. Pós-doutora e doutora em Educação Escolar pela Universidade Estadual Paulista (Unesp), câmpus Araraquara. Técnica em Assuntos Educacionais na Universidade Federal de Goiás (UFG). E-mail: chaianemr @hotmail.com.

Fabiano Fortunato T. Santos. Doutor em Matemática pela Universidade de Brasília (UnB). Professor do Instituto de Matemática e Estatística da Universidade Federal de Goiás (UFG). E-mail: fabianoftds@ yahoo.com.br
} 
Neste estudo, o questionário foi escolhido para a coleta de dados por se entender que ele possibilita atingir um grande número de pessoas. Para tanto, também se optou pela ferramenta online, entendendo-se que, contatando os alunos por e-mail, e solicitando o preenchimento do formulário eletrônico, a colaboração com as respostas poderia ser significativa.

Para a realização desta pesquisa, os alunos do IME, que frequentam os cursos de Matemática (bacharelado e licenciatura) e Estatística (bacharelado), foram divididos em três grupos: alunos excluídos, alunos retidos e alunos regulares. Essa divisão foi feita por se acreditar que pode haver diferença na percepção desses grupos. Para cada grupo, foi aplicado um questionário online específico. Vale esclarecer que, neste estudo, foca-se especificamente nos alunos excluídos, de modo que outras análises abordarão a percepção dos demais grupos.

Portanto, foi feita uma pesquisa com os alunos excluídos do IME no primeiro semestre de 2017, por não renovarem vínculo com a UFG, visto que, entre as causas de evasão na $\mathrm{UFG}^{1}$ de 2006 a 2016, essa foi a principal delas, representando 45,5\% do total. Do curso de Matemática (bacharelado e licenciatura), foram excluídos 18 alunos, dos quais 5 responderam ao questionário, o que representa 27,8\% do total. Do curso de Estatística (bacharelado), 14 alunos foram excluídos, sendo que 6 deles, o que corresponde a 42,8\%, participaram da pesquisa. Logo, no geral, dos 32 excluídos do IME/UFG, 11 responderam ao questionário, o que significa 34,4\% da totalidade.

A partir das respostas dos alunos aos questionários, que constituem os dados primordiais desta pesquisa, buscou-se compreender tanto os fatores que os alunos atribuem como influenciadores da opção pelo curso em que estavam matriculados no momento da exclusão, como os elementos que os motivaram na decisão por abandonar o curso. Os dados foram interpretados e articulados com suportes teóricos. Portanto, a pesquisa possui abordagem quanti-qualitativa. Isso porque articula a dimensão quantitativa, que é marcada pelo uso da quantificação, seja na coleta de informações ou no tratamento das mesmas, por meio de técnicas estatísticas (RICHARDSON, 1989), com a dimensão qualitativa, que tem como foco a interpretação, ao invés da quantificação (CASSEL; SYMON, 1994).

\footnotetext{
${ }^{1}$ A evasão de curso na UFG pode se dar pelos seguintes fatores: exclusão do aluno do curso, o que pode se dar pelos seguintes fatores: não renovar vínculo com a instituição, desistência do curso, transferência para outras instituições de educação superior, esgotamento do prazo para integralizar o curso, opção por outro curso da UFG, falecimento, e outras formas, o que compreende diversos tipos de reprovação (reprovação três vezes na mesma disciplina, reprovação por média e falta no semestre de ingresso, reprovação por média e falta em todas as disciplinas por dois semestres consecutivos).
} 
Vale esclarecer que esta se trata de uma pesquisa baseada em autodeclaração, ou seja, no que os próprios estudantes disseram a respeito de suas vivências no ambiente acadêmico, enquanto alunos do IME/UFG. Portanto, apesar de as fontes serem documentos, no caso, os questionários aplicados, o componente fundamental desta investigação são as declarações, que são permeadas de subjetividade. Logo, por mais que se tenha buscado extrair dados quantitativos dos questionários, não se pode desprezar que se tratam de dados construídos a partir de memórias.

\section{PERFIL DO ALUNADO DO IME/UFG}

O IME/UFG oferta, anualmente, 160 vagas, sendo 60 para Matemática (grau não definido), no turno vespertino; 50 para Matemática (licenciatura), turno noturno; e 50 para o curso de Estatística (bacharelado), turno noturno. É importante dizer que os alunos que ingressam no grau não definido têm do segundo ao quarto semestre de curso para definir a modalidade, podendo optar pelo bacharelado ou pela licenciatura.

É preciso considerar que cada um dos cursos ofertados pelo IME/UFG tem um perfil diferente, como se pode ver abaixo:

Perfil dos alunos do curso de Matemática - Licenciatura (IME/UFG)(2006-2016).

\begin{tabular}{|l|l|l|l|l|l|l|l|l|l|}
\hline $\begin{array}{l}\text { Ano de } \\
\text { ingresso }\end{array}$ & Ingressantes & Excluídos & $\%$ & Graduados & $\%$ & Ativos & $\%$ & Trancados & $\%$ \\
\hline 2006 & 66 & 29 & 43,9 & 37 & 56,1 & - & - & - & \\
\hline 2007 & 73 & 34 & 46,6 & 39 & 53,4 & - & - & - & - \\
\hline 2008 & 65 & 37 & 56,9 & 27 & 41,5 & 1 & 1,5 & - & - \\
\hline 2009 & 63 & 47 & 74,6 & 16 & 25,4 & - & - & - & - \\
\hline 2010 & 31 & 16 & 51,6 & 9 & 29,0 & 6 & 19,4 & - & - \\
\hline 2011 & 21 & 9 & 42,9 & 7 & 33,3 & 5 & 23,8 & - & - \\
\hline 2012 & 58 & 27 & 46,6 & 7 & 12,1 & 21 & 36,2 & 3 & - \\
\hline 2013 & 66 & 39 & 59,1 & 5 & 7,6 & 20 & 30,3 & 2 & 5,2 \\
\hline 2014 & 53 & 22 & 41,5 & - & - & 28 & 52,8 & 3 & 3,0 \\
\hline 2015 & 76 & 31 & 40,8 & - & - & 39 & 51,3 & 6 & 5,7 \\
\hline 2016 & 74 & 18 & 24,3 & - & - & 49 & 66,2 & 7 & 7,9 \\
\hline
\end{tabular}

Fonte: Os autores.

O curso de Matemática - licenciatura é o com maior número médio de ingressantes. De 2006 a 2016, entraram, em média, 58,6 alunos. O ano em que houve maior número de ingressantes foi 2015, com 76, e o ano com menor número foi 2011, com 21 alunos. Porém, desses ingressantes, poucos se formaram. A média dos alunos que ingressaram de 2006 a 2013 e que se graduaram foi 
de $32,3 \%$. É preciso ponderar que esse percentual pode aumentar, visto que ainda há alunos ativos dos anos de 2008, 2010, 2011, 2012 e 2013, e que ainda podem se formar.

Porém, esse quadro de alunos ainda ativos também pode aumentar o percentual de alunos excluídos do curso, que é bastante elevado, com média de 48,1\% de 2006 a 2016. O maior percentual de exclusão foi dos ingressantes de 2009, dos quais 74,6\% foram excluídos. Mas é preciso salientar que, dos 11 anos analisados, em quatro deles (2008, 2009, 2010 e 2013) o percentual de evasão foi maior que 50\%, o que é um dado alarmante. O menor percentual de evasão no curso foi em 2016, com 24,3\%. Entretanto, dos alunos ingressantes nesse ano, 66,2\% ainda estão ativos, o que significa que o panorama da exclusão pode sofrer alterações importantes. Também não se pode desconsiderar o percentual de trancamentos, que de 2012 a 2016 foi, em média, de 6,3\%, o que representa um abandono temporário do curso.

Já o perfil discente do curso de Matemática - bacharelado é o seguinte:

Perfil dos alunos do curso de Matemática - Bacharelado (IME/UFG)(2006-2016).

\begin{tabular}{|l|l|l|l|l|l|l|l|l|l|}
\hline $\begin{array}{l}\text { Ano de } \\
\text { ingresso }\end{array}$ & Ingressantes & Excluídos & $\%$ & Graduados & $\%$ & Ativos & $\%$ & Trancados & $\%$ \\
\hline 2006 & 14 & 6 & 42,9 & 8 & 57,1 & - & - & - & \\
\hline 2007 & 18 & 5 & 27,8 & 13 & 72,2 & - & - & - & \\
\hline 2008 & 16 & 9 & 56,3 & 6 & 37,5 & 1 & 6,3 & - & - \\
\hline 2009 & 7 & 3 & 42,9 & 4 & 57,1 & - & - & - & - \\
\hline 2010 & 11 & 3 & 27,3 & 7 & 63,6 & 1 & 9,1 & - & - \\
\hline 2011 & 6 & 2 & 33,3 & 3 & 50,0 & 1 & 16,7 & - & - \\
\hline 2012 & 14 & 5 & 35,7 & 2 & 14,3 & 7 & 50,0 & - & - \\
\hline 2013 & 12 & 2 & 16,7 & 2 & 16,7 & 7 & 58,3 & 1 & - \\
\hline 2014 & 10 & 4 & 40,0 & - & - & 5 & 50,0 & 1 & 8,3 \\
\hline 2015 & 6 & - & - & - & - & 6 & 100,0 & - & 10,0 \\
\hline 2016 & 9 & - & - & - & - & 8 & 88,9 & 1 & - \\
\hline
\end{tabular}

Fonte: Os autores.

A média de ingressantes no curso, de 2006 a 2016, foi de apenas 11,2 alunos, um número muito baixo. O ano em que houve maior número de ingressantes foi 2007, com 18, e os anos com menor número de alunos ingressantes foram 2011 e 2015, com 6 alunos. Vale lembrar que não há oferta de vagas no processo seletivo para o curso de Matemática - bacharelado. Os alunos que ingressaram nesse curso, a cada ano, são os originalmente matriculados no grau não definido, e que optam por essa modalidade, quando da definição.

Com menos alunos que a licenciatura, o bacharelado em Matemática teve, em média, 40,1\% alunos graduados de 2006 a 2013. O maior percentual de graduados foi dos ingressantes de 2007, 
dos quais $72,2 \%$ se formaram. Já os menores percentuais de graduados foram os ingressantes de 2012 e 2013. Contudo, desses alunos, 50\% e 58,3\%, respectivamente, ainda estão ativos, o que pode ocasionar uma mudança no panorama de conclusão do curso. Já a média de exclusão dos ingressantes de 2006 a 2014 foi de 35,9\%, muito expressiva. O maior percentual de exclusão foi em 2008, com 56,3\%. Mas um dado que merece nota é que, dos ingressantes no curso em 2014, 40\% já foram excluídos, e $50 \%$ ainda estão ativos. Logo, se houver mais excluídos desse período, pode ser que ele se torne o mais expressivo em termos de exclusão. E, no curso em questão, a média de trancamentos em 2013, 2014 e 2016 foi de $9,8 \%$.

Já o perfil dos alunos da Estatística - bacharelado delineia-se da seguinte maneira:

Perfil dos alunos do curso de Estatística - Bacharelado - IME/UFG - 2006-2016

\begin{tabular}{|c|c|c|c|c|c|c|c|c|c|}
\hline $\begin{array}{l}\text { Ano de } \\
\text { ingresso }\end{array}$ & Ingressantes & Excluídos & $\%$ & Graduados & $\%$ & Ativos & $\%$ & Trancados & $\%$ \\
\hline 2009 & 33 & 29 & 87,9 & 3 & 9,1 & 1 & 3,03 & - & - \\
\hline 2010 & 40 & 29 & 72,5 & 9 & 22,5 & 2 & 5,0 & - & - \\
\hline 2011 & 28 & 21 & 75,0 & 3 & 10,7 & 4 & 14,3 & - & - \\
\hline 2012 & 40 & 27 & 67,5 & 1 & 2,5 & 11 & 27,5 & 1 & 2,5 \\
\hline 2013 & 40 & 27 & 67,5 & - & - & 11 & 27,5 & 2 & 5,0 \\
\hline 2014 & 39 & 26 & 66,7 & - & - & 11 & 28,2 & 2 & 5,1 \\
\hline 2015 & 43 & 33 & 76,7 & - & - & 7 & 16,3 & 3 & 7,0 \\
\hline 2016 & 52 & 22 & 42,3 & - & - & 23 & 44,2 & 7 & 13,5 \\
\hline
\end{tabular}

Fonte: Os autores.

O curso de Estatística - bacharelado teve início em 2009, e, desde então até 2016, teve, em média, 39,4 alunos ingressantes por ano. $\mathrm{O}$ ano em que houve maior número de ingressantes foi 2016, com 52, e o ano com menor número de alunos ingressantes foi 2011, com 28 alunos. Esse é o curso com menor taxa de graduação do IME/UFG, visto que o percentual de conclusão do curso dos ingressantes de 2009 a 2012 foi de apenas 11,2\%. Dos ingressantes de 2013 a 2016, ainda não há alunos graduados, em razão de que o prazo regular para integralização do curso é 4,5 anos, e, portanto, esses alunos ainda não ultrapassaram o prazo para se graduar.

Como a taxa de conclusão do curso é baixa, a média de exclusão é extremamente elevada, de $69,4 \%$ no período de 2009 a 2016. O maior percentual de exclusão foi com os ingressantes de 2009, a primeira turma do curso, dos quais $87,9 \%$ foram excluídos. E o menor percentual foi o de 2016. Mas não se pode desconsiderar que, dos ingressantes desse período, 44,2\% ainda estão ativos, e, portanto, ainda podem ser excluídos. A exclusão no curso de Estatística é tão acentuada que, dos cursos com maior número de desistência da Regional Goiânia da UFG, no período de 2008 a 2016 , ele ocupa a $17^{\mathrm{a}}$ posição. 
Diante desses indicativos, e considerando o que eles representam, entendeu-se como necessário se voltar para uma compreensão qualitativa da problemática da evasão no IME/UFG. Por isso, optou-se por buscar informações mais detalhadas, obtidas pelos próprios sujeitos excluídos, para compreender as causas desse fenômeno.

\section{O Que Apontam os Alunos}

Um dado extremamente relevante para compreender os contornos da exclusão em qualquer curso é saber do interesse do aluno em relação ao mesmo. Por isso, indagou-se se o curso em que os alunos do IME/UFG estavam matriculados no momento da exclusão era sua primeira opção de graduação, ao que responderam o seguinte:

O curso no qual estava matriculado era sua primeira opção de graduação?

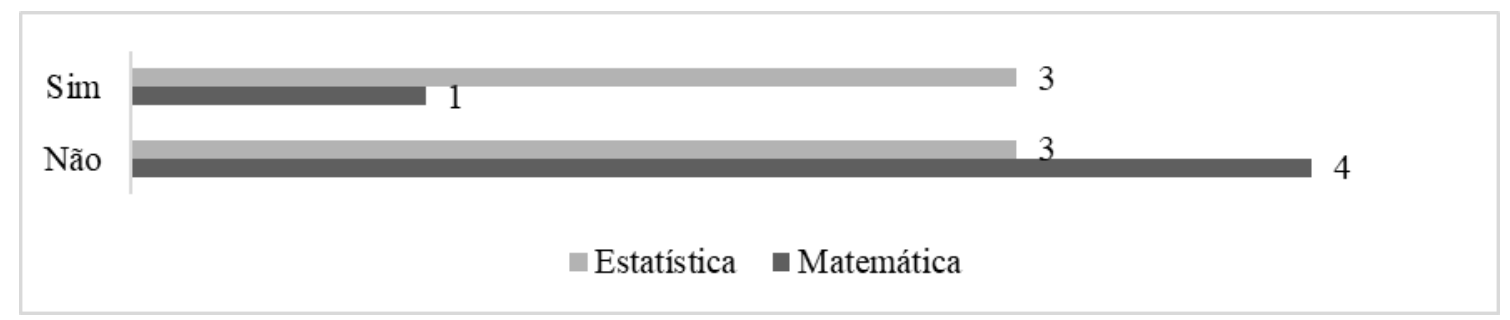

Fonte: Os autores.

Do curso de Matemática, dos cinco alunos que responderam ao questionário, quatro deles afirmaram que o curso, na habilitação que cursavam, não era sua primeira opção de graduação, indicando que tinham como interesse os seguintes cursos: Matemática (mas outra habilitação), Ciências da Computação, Engenharia Mecânica e Engenharia Elétrica. Já dos alunos excluídos da Estatística, três responderam que esse era sua primeira opção de curso, e os outros três afirmaram que não, indicando como primeira opção os cursos de Economia, Matemática e Administração. Logo, a causa da evasão dos alunos do curso pode estar relacionada com a escolha inadequada.

Nogueira et al. (2017) afirmam que, com o Sistema de Seleção Unificada (Sisu), o estudante pode fazer simulações, vendo em quais cursos tem reais condições de ser aprovado, o que estimula uma escolha estratégia, para não ser reprovado. Assim, o estudante acaba ajustando suas preferências ao que é realmente possível de ser aprovado, mesmo que não seja no curso ou instituição que almeje. E esse quadro acaba acarretando em dois problemas: a não matrícula após a aprovação, e a evasão após o ingresso.

Questionados sobre as razões que os levaram a optar pelo seu curso, os alunos responderam o seguinte:

O que o levou a optar pelo curso? 


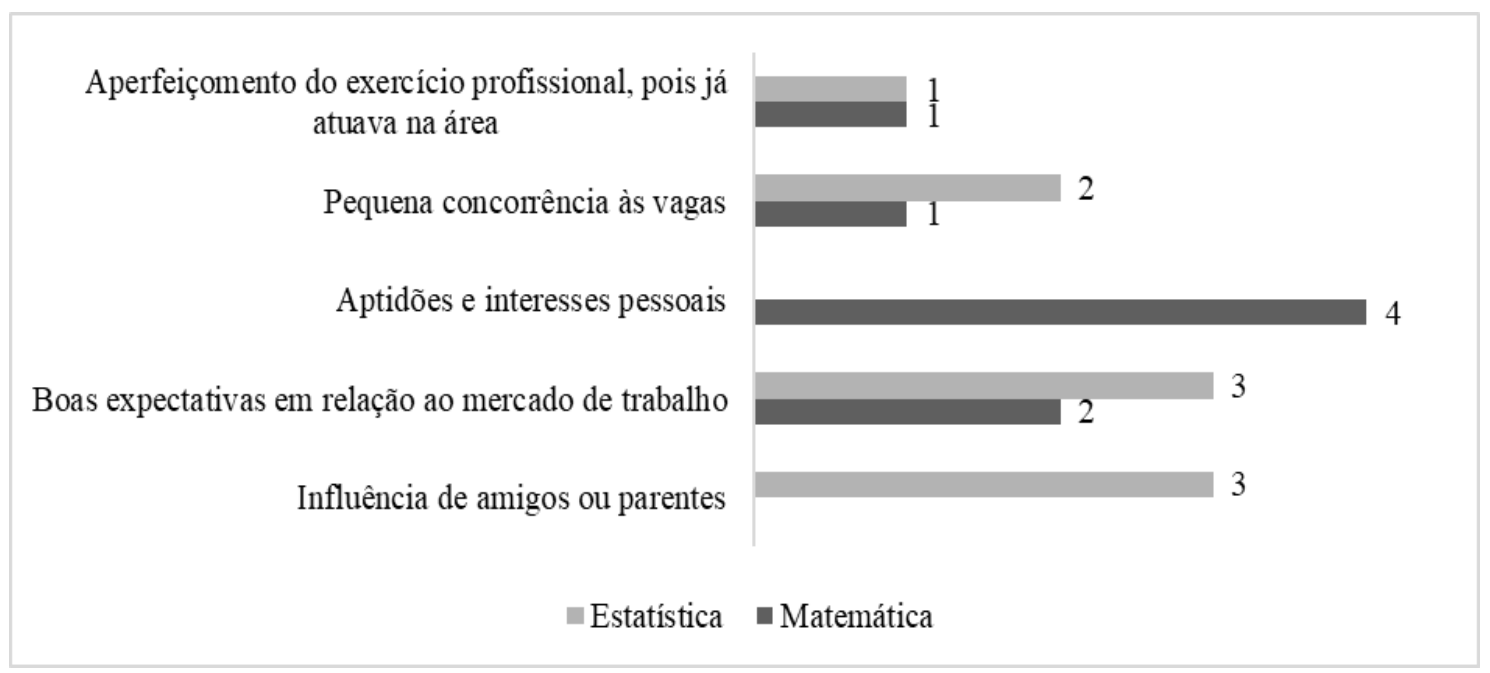

Fonte: Os autores.

Dos cinco alunos da Matemática, quatro mencionaram o fator aptidões e interesses pessoais. Esse é um fator de grande influência na escolha pela graduação, haja vista que os alunos tendem a optar por áreas de conhecimento em que se destacam na educação básica. Um dos alunos inclusive afirmou que, além das aptidões e interesses próprios, o curso foi escolhido por possibilitar o aperfeiçoamento do seu exercício profissional, pois já atuava na área. Dois alunos da Matemática também mencionaram que a escolha do curso foi determinada pelas boas expectativas em relação ao mercado de trabalho. E outro aluno afirmou que sua escolha também foi condicionada à pequena concorrência às vagas no processo de seleção.

Já dos seis alunos da Estatística, três mencionaram a influência de amigos ou parentes. Essa influência na seleção de uma profissão a seguir é realmente determinante. Isso porque, conforme Sousa (2005), o processo de escolha por um curso de graduação se inicia precocemente. "Durante um longo período, a criança conhece o mundo que a cerca através do olhar de seus pais e dos adultos significativos em sua vida, as profissões, o significado atribuído ao trabalho e suas representações sociais estão inseridas nesse contexto" (SOUSA, 2005, p. 18). Por assim ser, segundo a autora, o jovem acaba se sentindo confuso ao ter que diferenciar suas expectativas e desejos dos de seus familiares, querendo agradá-los.

Três estudantes da Estatística também apontaram o fator boas expectativas em relação ao mercado de trabalho. Nesse caso, a escolha é feita considerando as possibilidades de ter êxito não apenas na vida acadêmica, mas também na vida profissional. Muitos estudantes fazem suas escolhas sob influência de quais profissões são mais prestigiadas, ou que estão mais em "alta", demandando mais trabalhadores, no momento da sua decisão. Dois alunos também mencionaram a pequena concorrência às vagas, o que sinaliza que a escolha é feita pela maior possibilidade de ingresso; e um citou o aperfeiçoamento profissional, pois já atuava na área. 
No caso do aluno que escolhe o curso menos concorrido, para não ficar fora da universidade, ele acaba ingressando em um curso que não é o que ele realmente deseja, mas que é o possível, de acordo com sua pontuação no Exame Nacional do Ensino Médio (Enem). Esse fato mostra que é preciso ponderar que a escolha do curso é fortemente condicionada pelas reais possibilidades de ingressar em uma instituição de educação superior. Isso porque as escolhas refletem as condições efetivas de se poder ou não optar pelo curso de sua vocação.

Para os estudantes provenientes de estratos sociais menos favorecidos socioeconomicamente, o ingresso em cursos de maior prestígio social, e mais concorridos - como é o caso de Medicina, Direito e Engenharias, tradicionalmente - é um desejo muitas vezes inalcançável. Mesmo com a Lei 12.711/2012 - que reserva, no mínimo, 50\% de suas vagas para estudantes que tenham cursado o ensino médio em escolas públicas, o que pressupõe serem os mais vulneráveis socioeconomicamente - o acesso aos cursos mais elitizados ainda é uma lacuna a ser superada pelas políticas de democratização da educação superior.

É preciso concordar com Sobrinho (2010), que reconhece um processo de autoexclusão, que ocorre quando jovens que são suprimidos do acesso a bens culturais acabam naturalizando a situação de exclusão social. Dessa maneira, tendem a optar por cursos menos seletivos, e de menor prestígio social, por perceberem nesses maior possibilidade de aprovação.

Bardagi e Hutz (2009, p. 103) salientam que: “[...] o processo de escolha inicial do curso, quando pobre e baseado em informações estereotipadas e inconsistentes, é um facilitador potencial da evasão, pois leva a uma menor integração universitária e não cria condições de enfretamento das dificuldades por parte do aluno". Nesse sentido, acredita-se que uma escolha adequada do curso de graduação pode reduzir significativamente a evasão.

Para uma escolha de curso adequada, a orientação vocacional é fundamental, seja para alunos da educação básica, ou mesmo para aqueles que já estão na educação superior, mas que têm intenção de mudar de curso. No entendimento de Sousa (2005),

A consolidação e sistematização de um serviço de orientação e acompanhamento psico-pedagógico justifica-se, sobretudo, pelos desdobramentos de suas ações, a sua representatividade e caráter preventivo, que contribuem para a redução da evasão na educação superior e a existência de futuros profissionais insatisfeitos no mercado de trabalho (SOUSA, 2005, p. 61-62).

Todavia, é preciso ponderar que, para aqueles estudantes que têm sua escolha condicionada à sua condição socioeconômica; para os que precisam escolher um curso que seja possível conciliar 
com o trabalho, normalmente no turno noturno; para os que têm uma família para cuidar, a orientação vocacional não tem efeito. Daí a necessidade de se buscar entender as demandas individuais de cada aluno e atuar de maneira pontual, o que, considerando a dimensão do corpo discente da UFG, representa um grande desafio.

Além do que motivou a escolha dos alunos pelo curso, é preciso entender o que os levou a desistir do mesmo. Portanto, averiguou-se a quantidade de reprovações, com vistas a descobrir a influência do baixo desempenho acadêmico na opção pelo abandono do curso.

Você teve reprovação em quantas disciplinas?

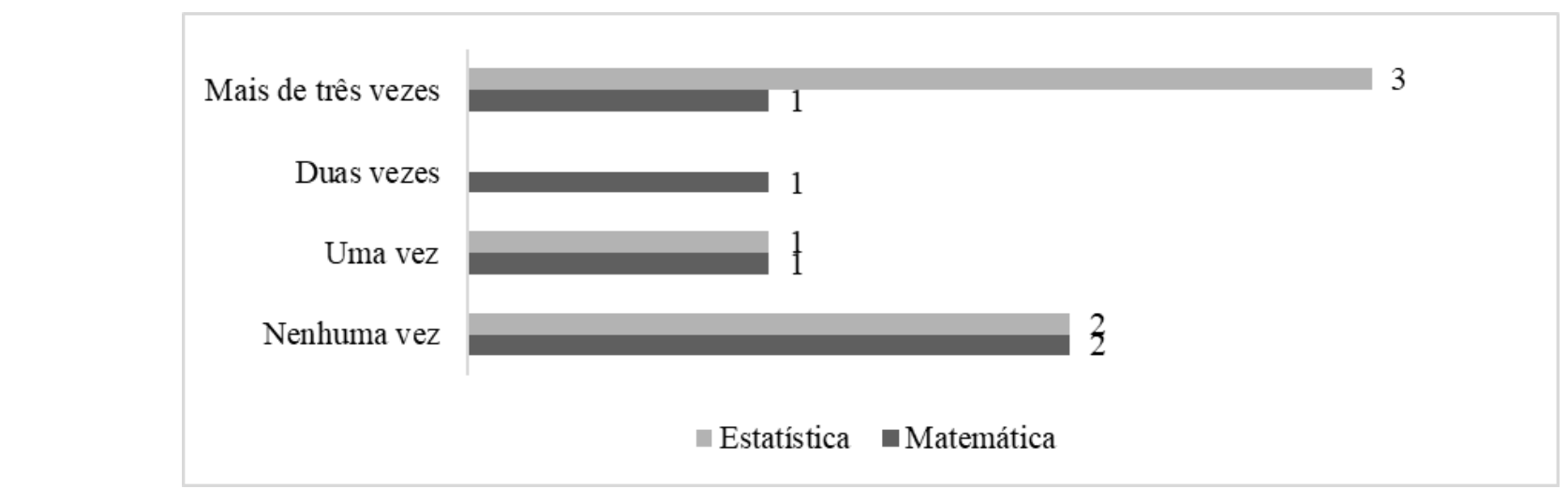

Fonte: Os autores.

Dois alunos da Matemática afirmaram que não tiveram nenhuma reprovação. Esses alunos ingressaram em 2014 e 2015, ou seja, frequentaram dois ou três anos de curso. Esse é um indicativo de que esses estudantes tinham um bom desempenho. Outro aluno disse que reprovou uma única vez, outro disse que teve duas reprovações, e outro três ou mais. Considerando a dificuldade que normalmente é atribuída ao curso de Matemática, esses alunos participantes da pesquisa tinham um desempenho satisfatório, no geral, o que não justifica o abandono do curso por dificuldades de aprendizagem.

Dos alunos excluídos do curso de Estatística, por sua vez, três afirmaram que tiveram três reprovações, e um duas reprovações, um somente uma, e dois alunos nunca reprovaram. Os alunos que nunca reprovaram são ingressantes de 2016, e o aluno que reprovou uma única fez é ingressante de 2017. Os demais alunos, com mais de três reprovações, são ingressantes de 2013 e 2014. Nesse caso, não se pode desconsiderar o reflexo do baixo desempenho no processo de evasão.

Diante disso, Houri (2017, p. 153) salienta que: “[...] os alunos precisariam de apoio de ordem pedagógica e institucional visto que, muitas vezes, sentem grande dificuldade de acompanhar as aulas e alcançar o desempenho demandado para prosseguir seus cursos". Esse obstáculo é um fato concreto, posto que o grau de dificuldade que os alunos atribuem ao curso é elevado, como se pode ver no gráfico abaixo: 
Qual o grau de dificuldade você atribui ao curso?

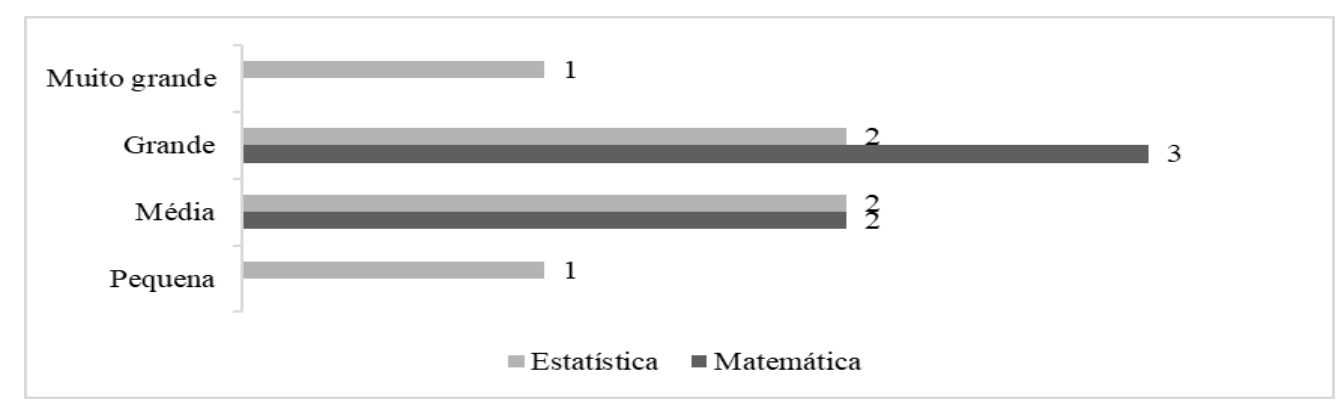

Fonte: Os autores.

Dos alunos excluídos da Matemática, por mais que eles tivessem apresentado um bom desempenho, com poucas reprovações no período em que estavam ativos no curso, eles disseram que a dificuldade do curso é média (dois alunos) e grande (três alunos). Já dos alunos da Estatística, a avaliação foi de que a dificuldade do curso é muito grande (um aluno), grande (dois alunos) e média (dois alunos). Apenas um aluno afirmou que o grau de dificuldade do curso é pequeno, apesar de o mesmo ter reprovado em uma disciplina.

Diante desse panorama de alunos com dificuldades de ordem pedagógica, ou que entendem o curso como difícil,

[...] é preciso enfrentar a realidade de alunos que chegam, muitas vezes, com falhas na formação básica, o que acaba por refletir no seu aproveitamento na educação superior, quanto é preciso também rever práticas pedagógicas comportamentais dos professores e, possivelmente, currículos e muitas outras questões estruturais e ou conjunturais vinculadas às próprias instituições e seus respectivos cursos (HOURI, 2017, p. 154).

Quando interrogados sobre os motivos que os levaram a abandonar o curso de graduação, os alunos manifestaram o seguinte: 


\section{O que o levou a abandonar o curso?}

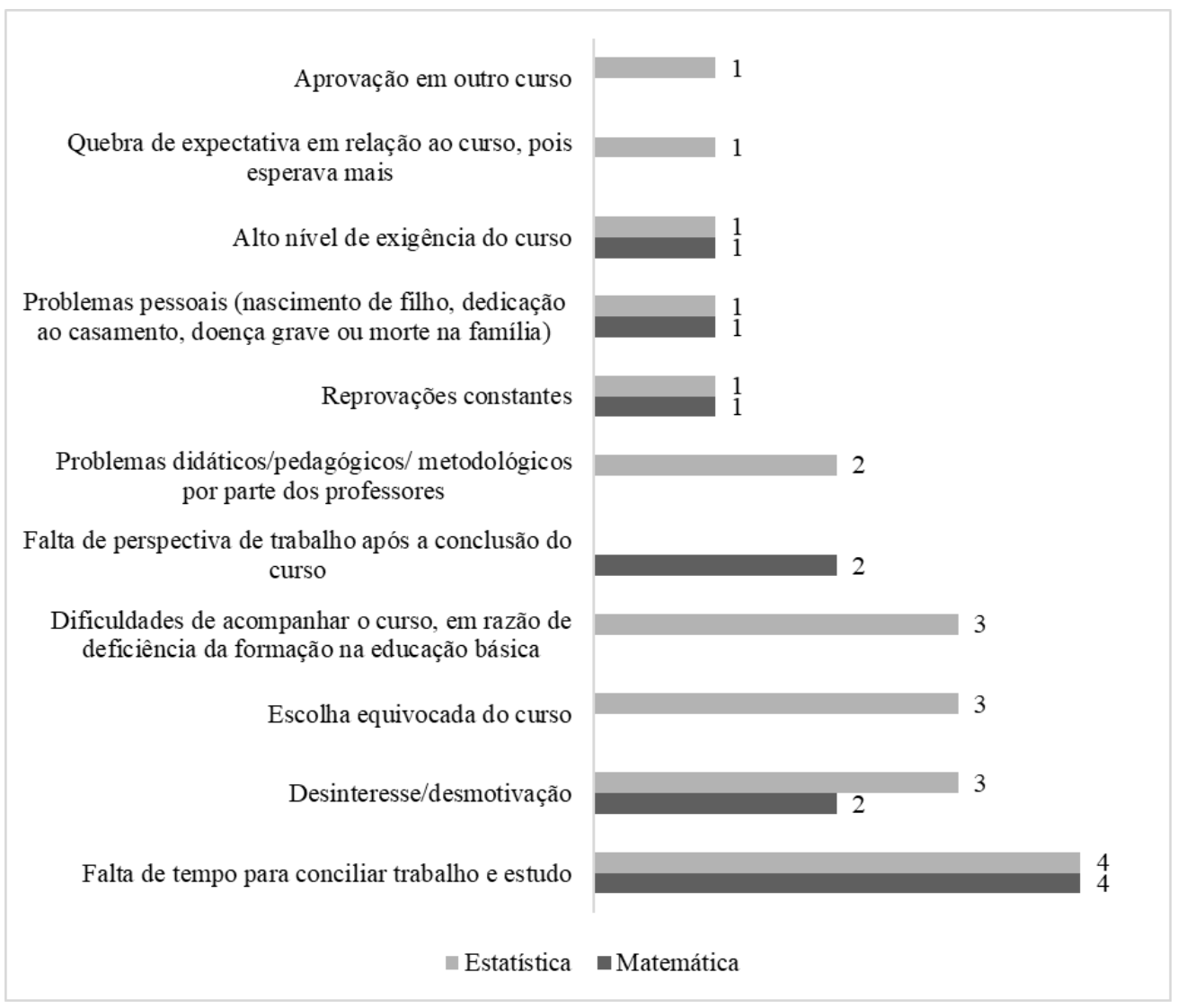

Fonte: Os autores.

No curso de Matemática, o fator preponderante, presente em quatro das cinco respostas, foi a falta de tempo para conciliar trabalho e estudo. Dos alunos da Estatística, quatro também indicaram esse fator. Isso se explica pelo fato de que, dos excluídos da Matemática, quatro eram alunos trabalhadores e trabalhavam o dia todo, e apenas um afirmou que apenas estudava. E dos alunos da Estatística, quatro afirmaram trabalhar um período inteiro por dia, e dois declararam apenas estudar, como se pode ver no gráfico a seguir:

Qual atividade exercia no momento do abandono do curso?

Não trabalhava, apenas estudava
Trabalhava apenas um período por dia
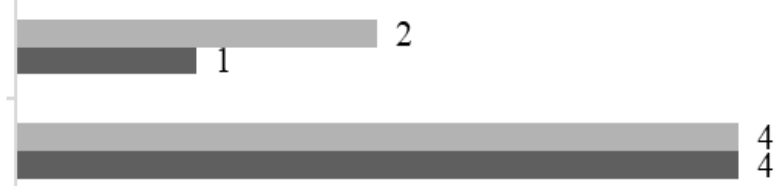

Estatística $\quad$ Matemática

Fonte: Os autores.

$\mathrm{O}$ fato de grande maioria dos estudantes trabalhar pode estar relacionado à sua vulnerabilidade socioeconômica, reflexo de sua renda familiar baixa: 
Qual sua renda familiar no momento do abandono do curso?

Fonte: Os autores.

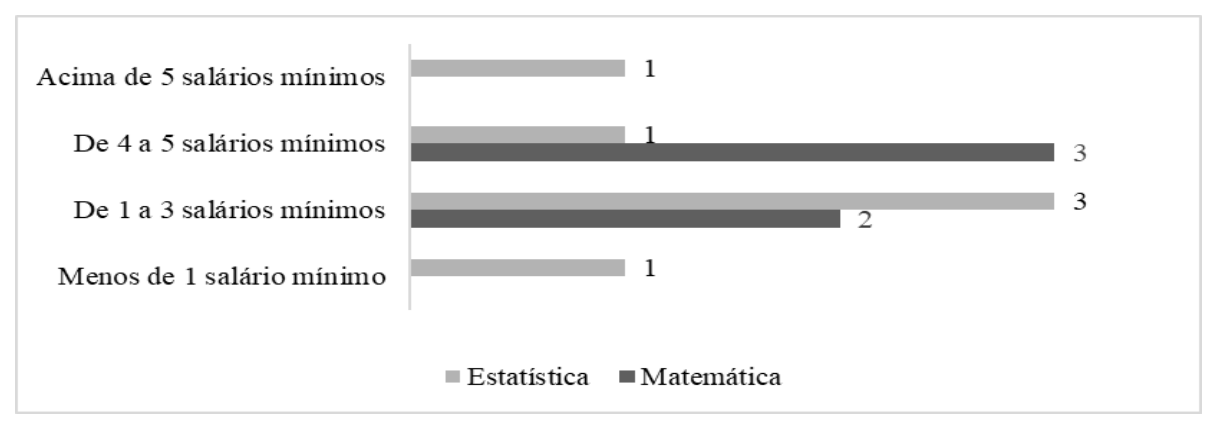

Dos alunos da Matemática, três declararam renda familiar entre 4 e 5 salários, e dois entre 1 e 3 salários. Já dos Estudantes da Estatística, o quadro de vulnerabilidade socioeconômica mostrouse ainda mais acentuado, visto que um estudante afirmou possuir renda familiar de menos de 1 salário mínimo, três entre 1 a 3 salários mínimos, 1 renda entre 4 a 5 salários, e 1 acima de 5 salários mínimos. Segundo critério utilizado pelo Instituto Brasileiro de Geografia e Estatística (IBGE), a classe social, de acordo com a renda familiar, é a seguinte: $\mathrm{A}$ = acima de vinte salários mínimos; $\mathrm{B}=$ entre dez e vinte salários mínimos; $\mathrm{C}=$ entre quatro e dez salários mínimos; $\mathrm{D}=$ entre dois e quatro salários mínimos; e E = até dois salários mínimos.

Portanto, o perfil dos alunos excluídos do IME/UFG é primordialmente das classes C, D e E. De acordo com a Andifes (1997), no Fórum Nacional de Pró-Reitores de Assuntos Comunitários e Estudantil (Fonaprace), os alunos dessas classes são aqueles que compõem o perfil da demanda potencial por assistência estudantil. Mas muitos estudantes, por não contarem com a assistência estudantil, pois o programa não consegue suprir a demanda de toda a universidade, acabam recorrendo ao trabalho para suprir suas necessidades básicas.

Santos e Silva (2011, p. 256) reconhecem que: “O trabalho, buscado por esses jovens como um fator de autonomia e/ou independência econômica em relação a suas famílias, concorre fortemente com a obtenção de um diploma, fragilizando suas trajetórias acadêmicas". E as autoras afirmam que, para os estudantes que abandonam a universidade em razão do trabalho, essa é uma situação adversa, visto que eles reconhecem a relevância da trajetória escolar, tanto para a formação intelectual como para a mobilidade social.

Além da necessidade de conciliar trabalho e estudo como determinante da exclusão, no grupo dos alunos da Matemática, os fatores falta de perspectiva de trabalho após a conclusão do curso e desinteresses/desmotivação apareceram na sequência, sendo mencionados duas vezes; e, por fim, foram elencados, uma única vez, os seguintes fatores: alto nível de exigência do curso, 
reprovações constantes e problemas pessoais (nascimento de filho, dedicação ao casamento, dedicação ao casamento, doença grave ou morte na família).

Dos alunos da Estatística, três apontaram os fatores: desinteresse/desmotivação, escolha equivocada do curso e dificuldades de acompanhar o curso, em razão de deficiência da formação na educação básica. Dois alunos também mencionaram os problemas didáticos/pedagógicos/ metodológicos por parte dos professores. E por fim, houve alunos que citaram, uma única vez, os fatores: reprovações constantes, problemas pessoais (nascimento de filho, dedicação ao casamento, doença grave ou morte na família), alto nível de exigência do curso, quebra de expectativa, pois esperara mais, e aprovação em outro curso.

Sobre as dificuldades de acompanhar o curso, em razão de deficiência da formação na educação básica, é preciso concordar com Silva (2014, p. 90), segundo o qual “A entidade educacional deverá preparar didaticamente seu corpo docente para ensinar o aluno que recebe e não o aluno que gostaria de receber”. O autor afirma que as instituições recebem alunos com defasagem de conhecimento elementar, e cabe a elas se preparar para detectar, ainda no primeiro semestre do curso, as deficiências básicas que podem comprometer o desempenho acadêmico dos alunos, de modo a elaborar programas de recuperação (SILVA, 2014).

Vale demarcar que nenhum dos alunos participantes da pesquisa indicou os fatores: problemas financeiros; problemas de relacionamento com os colegas e/ou professores; e mudança de endereço, que também eram opções do questionário.

Por fim, questionados sobre sua atual situação acadêmica, as respostas foram as seguintes:

\section{Qual é sua situação acadêmica atual?}

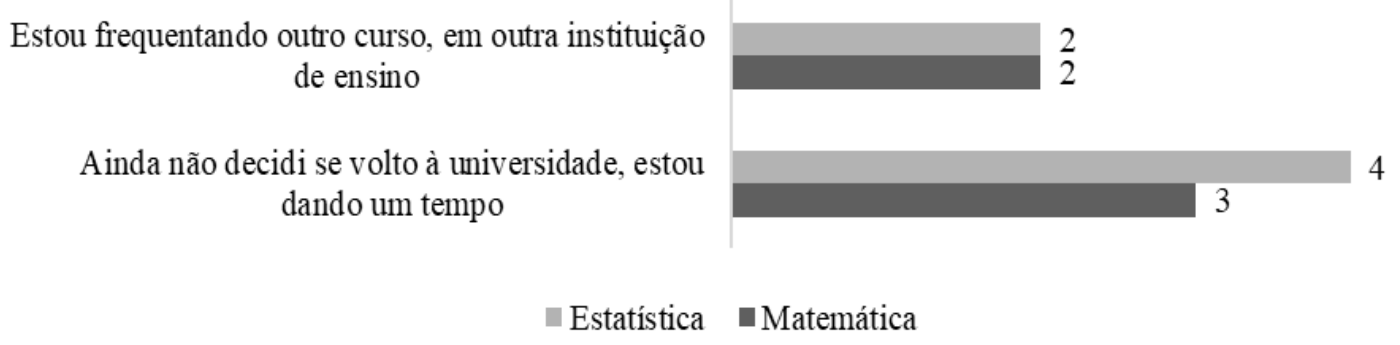

Fonte: Os autores.

Do curso de Matemática, três alunos disseram que ainda não decidiram se voltam à universidade, e estão dando um tempo nos estudos. Os dois outros estudantes afirmaram que estão frequentando outro curso, em outra instituição de ensino superior. O estudante que afirmou que sua primeira opção de curso de graduação era Ciência da Computação, está fazendo esse curso; e o estudante que disse que sua primeira opção era Engenharia Elétrica, está cursando Eletrotécnica. 
Dos alunos da Estatística, quatro afirmaram que não decidiram se voltam à universidade, estão dando um tempo, e dois estão frequentando outro curso, em outra instituição de ensino. Desses, o estudante que disse que sua primeira opção de curso era Economia, está cursando Direito; e o que tinha como interesse o curso de Administração, está cursando Gestão Financeira.

Esses dados reafirmam que o que levou os alunos a se evadirem do curso do IME/UFG Matemática ou Estatística - foi a insatisfação com o mesmo, em razão de ele não ser objeto de interesse desde o princípio. Assim, mudaram de curso e optaram pelo curso que almejavam, ou por um curso mais próximo disso. Apenas um estudante optou por um curso muito diferente de sua primeira opção (queria Economia e está fazendo Direito), o que aponta para a necessidade de uma orientação vocacional mesmo na graduação, para que os alunos não fiquem perdidos, fazendo escolhas precipitadas, mas que possam fazer escolhas mais assertivas.

\section{CONSIDERAÇÕES FINAIS}

Os resultados deste estudo evidenciaram que não há um único fator responsável pela evasão dos alunos dos cursos do IME/UFG. O problema, portanto, é multidimensional e decorre de uma série de fatores e questões que perpassam a vida pessoal e acadêmica dos alunos de forma muito particular, e culminam na sua decisão por abandonar o curso.

Pode-se dizer que a escolha acertada do curso é fundamental para a permanência exitosa do estudante na universidade até a conclusão do seu curso. Os alunos que se matriculam em um curso, mas que almejaram outro, acabam tendendo a encontrar uma possibilidade de realizar o seu sonho. Portanto, é comum que os alunos busquem os cursos que realmente desejam, ou pelo menos os mais aproximados a isso.

Outro problema que se destaca é o perfil de estudantes trabalhadores, que enfrentam dificuldades de conciliar o trabalho com os estudos, e acabam abandonando a trajetória acadêmica e priorizando o emprego. Os estudantes que enfrentam dificuldades financeiras têm uma trajetória acadêmica mais difícil, e, nesse aspecto, a assistência estudantil torna-se fundamental para tentar assegurar sua permanência na universidade.

Mas, para além de uma assistência de ordem financeira, por meio de bolsas, é preciso cuidar da assistência pedagógica, a ser destinada, sobretudo, aos estudantes que apresentam lacunas de aprendizado que não foram supridas na educação básica. Isso porque é comum que os estudantes que apresentem dificuldades de aprendizado, sobretudo no início do curso, abandonem o mesmo, por se sentirem incapazes. 
Diante do exposto neste estudo, que buscou compreender a percepção de determinado grupo de alunos sobre a evasão dos seus cursos de graduação, é preciso de enfatizar que:

[...] as características de perfil não são determinantes para a ocorrência de evasão, ou seja, ainda que um aluno tenha mais acentuada uma característica que o coloca na condição de evadido não significa, necessariamente, que isso aconteça, ou vice-versa. A caracterização do evadido apenas trabalha com uma possibilidade ou chance, não uma certeza determinística (VITELLI, 2013, p. 2013).

Logo, entende-se que os resultados deste estudo não são definitivos, tampouco gerais. Por isso, estão sendo desenvolvidas pesquisas pontuais, também com outros cursos da instituição, para compreender o fenômeno da evasão e suas particularidades, de acordo com o perfil dos cursos. 


\section{REFERÊNCIAS}

ANDIFES. Fórum Nacional de Pró-Reitores de Assuntos Comunitários e Estudantis. Primeira Pesquisa do Perfil Social, Cultural e Econômico dos Estudantes das IFES. Belo Horizonte: FONAPRACE, 1997.

BARDAGI, Marucia Patta; HUTZ, Claudio Simon. "Não havia outra saída": percepção dos alunos evadidos sobre o abandono do curso superior. Psico-USF, v. 14, n.1, p. 95-105, jan./abr. 2009.

BRASIL. Presidência da República. Lei. Lei 12.711, de 29 de agosto de 2012. Dispõe sobre o ingresso nas universidades federais e nas instituições federais de ensino técnico de nível médio e dá outras providências. Diário Oficial da União. Brasília, 2012.

CASSELL, Catherine; SYMON, Gillian. Qualitative methods in organizational research. London: Sage Publications, 1994.

DAVOK, Deisi Fries; BERNARD, Rosilane Pontes. Avaliação dos índices de evasão nos cursos de graduação da Universidade do Estado de Santa Catarina - UDESC. Avaliação, Campinas; Sorocaba, v.21, n. 2, p. 503-521, jul. 2016.

GIL, Antônio Carlos. Métodos e técnicas de pesquisa social. 5. ed. São Paulo: Atlas, 1999.

HOURI, Mônica de Souza. Evasão e permanência na educação superior - uma perspectiva discursiva. Tese (Doutorado em Educação) - Faculdade de Educação, Universidade Federal Fluminense, Rio de Janeiro, 2017.

INEP. Sinopse Estatística da Educação Superior 2015. Brasília: Inep, 2016. Disponível em: <http://portal.inep. gov.br/web/guest/sinopses-estatisticas-da-educacao-superior>. Acesso em: 30 ago. 2017.

NOGUEIRA, Cláudio M. Martins et al. Promessas e limites: o SISU e sua implantação na Universidade Federal de Minas Gerais. Educação em Revista, Belo Horizonte, n. 33, p. 1-31, 2017.

RICHARDSON, Roberto Jarry. Pesquisa social: métodos e técnicas. São Paulo: Atlas, 1989.

SANTOS, Georgina G.; SILVA, Lelia Custódio. A evasão na educação superior: entre debate social e objeto de pesquisa. In: SAMPAIO, S.M.R. (Orgs.). Observatório da vida estudantil: primeiros estudos. Salvador: EDUFBA, 2011.

SILVA, Argemiro Severiano. Retenção ou evasão - a grande questão social das instituições de educação superior. Dissertação de mestrado. Programa de Pós-Graduação em Direito Político e Econômico. Universidade Presbiteriana Mackenzie, 2014.

SOBRINHO, José Dias. Democratização, qualidade e crise da educação superior: faces da exclusão e limites da inclusão. Educação e Sociedade, Campinas, v. 31, n. 113, p. 1223-1245, out./dez. 2010.

SOUSA, Elizene M. Caliman. Orientação profissional nos cursos de graduação: contribuições e limites. Dissertação (Mestrado em Educação) - Departamento de Educação. Universidade Católica de Brasília, Brasília, 2005.

VITELLI, Ricardo Ferreira. Evasão em cursos de licenciatura: perfil do evadido, fatores intervenientes do fenômeno. Dissertação (Mestrado em Educação) - Unidade Acadêmica de Pesquisa e Pós-Graduação. Universidade do Vale do Rio dos Sinos, 2013. 


\section{RESUMO}

Este artigo tem como propósito discutir os condicionantes da evasão nos cursos do Instituto de Matemática e Estatística da Universidade Federal pela perspectiva dos alunos excluídos. Tem como fonte informações de registros acadêmicos na universidade. Ainda, foi aplicado um questionário eletrônico aos 32 alunos excluídos da unidade, dos quais 11 responderam, o que significa 34,4\% do total. A partir das respostas desses alunos, buscou-se analisar tanto os fatores que os levaram a optar pelo curso em que estavam matriculados no momento da exclusão, quanto os elementos que os influenciaram na decisão por abandonar o curso. Como resultado, constatou-se que a desistência do curso é fortemente influenciada pela escolha equivocada do curso, bem como pela dificuldade de conciliar trabalho e estudo.

Palavras-chave: Evasão. Instituto de Matemática e Estatística. Universidade Federal de Goiás.

\section{EVASION AT IME/UFG: THE POINT OF VIEW OF EXCLUDED STUDENTS}

\section{ABSTRACT}

The purpose of this article is to discuss the determinants of the evasion in the courses of Institute of Mathematics and Statistics of the Federal University of Goiás from the perspective of the excluded students. Has as a source information on academic records at the university. Also, an electronic questionnaire was applied to the 32 students excluded from the unit, of whom 11 answered, which means $34.4 \%$ of the total. From the answers of these students, we sought to analyze both the factors that led them to choose the course in which they were enrolled at the time of exclusion, and the elements that influenced them in the decision to leave the course. As a result, it was found that dropout of the course is strongly influenced by the wrong choice of course, as well as by the difficulty of reconciling work and study.

Keywords: Evasion. Mathematics and Statistics Institute. Federal University of Goias.

\section{EVASIÓN EN EL IME/UFG: EL PUNTO DE VISTA DE LOS ALUMNOS EXCLUIDOS}

\section{RESUMEN}

Este artículo tiene como propósito discutir los condicionantes de la evasión en los cursos del Instituto de Matemáticas y Estadística de la Universidad Federal por la perspectiva de los alumnos excluidos. Tiene como fuente información de registros académicos en la universidad. Además, se aplicó un cuestionario electrónico a los 32 alumnos excluidos de la unidad, de los cuales 11 respondieron, lo que significa el 34,4\% del total. A partir de las respuestas de estos alumnos, se buscó analizar tanto los factores que los llevaron a optar por el curso en que estaban matriculados en el momento de la exclusión, como los elementos que los influenciaron en la decisión por abandonar el curso. Como resultado, se constató que la desistencia del curso está fuertemente influenciada por la elección equivocada del curso, así como por la dificultad de conciliar trabajo y estudio.

Palabras clave: Evasión. Instituto de Matemáticas y Estadística. Universidad Federal de Goiás. 